\title{
RESEARCH
}

Open Access

\section{Pooled prevalence and determinants of skilled birth attendant delivery in East Africa countries: a multilevel analysis of Demographic and Health Surveys}

Zemenu Tadesse Tessema* (i) and Getayeneh Antehunegn Tesema

\begin{abstract}
Introduction: Skilled health professional assisted delivery is an effective strategy to reduce maternal and newborn mortality. Skilled assistant delivery can prevent about 16-33\% of maternal and newborn mortality. Despite the commitments of the government to assure home free delivery, majority of the births in Sub-Saharan Africa are attended by traditional birth attendants. As to our search of the literature, there is limited evidence on the prevalence and determinants of skilled delivery in East African countries. Therefore, this study aimed to estimate the pooled prevalence and determinants of skilled birth attendant delivery in East Africa Countries.

Methods: Pooled analysis was done based on Demographic and Health Surveys conducted in the 12 East African countries from 2008 to 2017. A total weighted sample of 141,483 women who gave birth during the study period was included in the study. The pooled prevalence of skilled birth attendance was estimated using STATA version 14. Intra-class Correlation Coefficient, Median Odds Ratio, Proportional Change in Variance, and deviance were used for model fitness and comparison. The multilevel multivariable logistic regression model was fitted to identify determinants of skilled birth attendance in the region. Adjusted Odds Ratio with its 95\% Confidence Interval was used to declare significant determinants of skilled birth attendants.

Results: The pooled prevalence of skilled birth attendant in East African countries were 67.18\% (95\% Cl:66.98, 67.38) with highest skilled birth attendant in Rwanda (90.68\%) and the lowest skilled birth attendant in Tanzania (11.91\%). In the Multilevel multivariable logistic regression model; age 15-24 (Adjusted Odds Ratio (AOR) = 1.14, 95\%Cl:1.09, 1.18), age 25-49(AOR $=1.16,95 \% \mathrm{Cl}: 1.10,1.23)$, primary women education $(\mathrm{AOR}=1.57,95 \% \mathrm{Cl}: 1.51,1.63)$, secondary and above women education $(\mathrm{AOR}=2.85,95 \% \mathrm{Cl}: 1.73,3.01)$, primary husband education $(\mathrm{AOR}=1.11,95 \% \mathrm{Cl}=1.07,1.15)$, secondary and above husband education ( $A O R=1.46,95 \% \mathrm{Cl}=1.40,1.53)$, middle wealth index $(\mathrm{AOR}=1.43,95 \% \mathrm{Cl}=1.38,1.49)$, rich wealth index $(\mathrm{AOR}=2.38,95 \% \mathrm{Cl}=2.28,2.48)$, had $\mathrm{ANC}$ visit $(\mathrm{AOR}=1.68,95 \% \mathrm{Cl}=1.62,1.73)$, multiple gestation ( $\mathrm{AOR}=$ $2.06,95 \% \mathrm{Cl}=1.90,2.25)$, parity $2-4(\mathrm{AOR}=0.65,95 \% \mathrm{Cl}=0.61,0.69)$, parity $5+(\mathrm{AOR}=0.44,95 \% \mathrm{Cl}=0.41,0.47)$, accessing health care not big problem ( $A O R=1.32,95 \% \mathrm{Cl}=1.28,1.36)$, residence $(A O R=0.43,95 \% \mathrm{Cl}=0.41,0.45)$ and being Burundi resident $(\mathrm{AOR}=0.77,95 \% \mathrm{Cl}=0.70,0.85)$ were significantly associated with skilled assisted delivery.

(Continued on next page)
\end{abstract}

\footnotetext{
*Correspondence: zemenut1979@gmail.com

Department of Epidemiology and Biostatistics, Institute of Public Health, College of Medicine and Health Sciences, University of Gondar, Gondar, Ethiopia
}

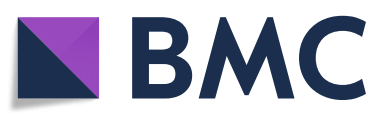

C C The Author(s). 2020 Open Access This article is licensed under a Creative Commons Attribution 4.0 International License, which permits use, sharing, adaptation, distribution and reproduction in any medium or format, as long as you give appropriate credit to the original author(s) and the source, provide a link to the Creative Commons licence, and indicate if changes were made. The images or other third party material in this article are included in the article's Creative Commons licence, unless indicated otherwise in a credit line to the material. If material is not included in the article's Creative Commons licence and your intended use is not permitted by statutory regulation or exceeds the permitted use, you will need to obtain permission directly from the copyright holder. To view a copy of this licence, visit http://creativecommons.org/licenses/by/4.0/ The Creative Commons Public Domain Dedication waiver (http://creativecommons.org/publicdomain/zero/1.0/) applies to the data made available in this article, unless otherwise stated in a credit line to the data. 


\begin{abstract}
(Continued from previous page)
Conclusion: Skilled birth attendance at birth in the East Africa countries was low. Maternal age, women and husband education, wealth index, antenatal care visit, multiple gestations, parity, accessing health care, residence, and living countries were major determinants of skilled attendant delivery. Strategies to increase the accessibility and availability of healthcare services, and financial support that targets mothers from poor households and rural residents to use health services will be beneficial. Health education targeting mothers and their partner with no education are vital to increasing their awareness about the importance of skilled birth attendance at birth.
\end{abstract}

Keywords: Skilled birth attendant, East Africa, Pooled analysis, DHS, Multilevel analysis

\section{Introduction}

Every day, about 830 women die from preventable causes related to pregnancy and childbirth, of which $99 \%$ of all maternal deaths occur in developing countries [1]. Worldwide, maternal mortality fell from 385 deaths per 100,000 livebirths in 1990 to 216 deaths per 100,000 livebirths in 2015 , which is declined by $44 \%$ [2, 3]. Sustainable Development Goal (SDG) goal 3 target 3.1 calls for reduction of maternal mortality ratio less than 70 per 100,000 live births between 2016 to 2030 [4]. Worldwide, 34\% of deliveries have no skilled birth attendant. That is 45 million birth occurred at home without skilled birth health personnel each year [5]. Sub-Saharan Africa has also shown progress over the same period on skilled birth attendance, and by $2012-2017$ over $50 \%$ of births were attended by skilled health personnel [6].

Skilled Birth Attendant (SBA) offers a safety and lifesustaining environment for both mothers and newborns thereby reducing the chance of complications [2]. Although it has difficult to establish a causal relationship between skilled birth attendance and maternal mortality, estimates suggested that skilled birth attendants present at birth could prevent around 16 to $33 \%$ of maternal death [7].

The East African countries that include Burundi, Ethiopia, Comoros, Uganda, Rwanda, Tanzania, Mozambique, Madagascar, Zimbabwe, Kenya, Zambia, and Malawi are among the world's poor countries with poor accessibility and affordability of maternal health care services [8].

Different scholars studied skill birth attendants at a specific population in different parts of East African Country. Studies conducted in Zambia reported that at least one ANC visit and poor economic status of respondents were associated with SBA [9]. Other scholars from Ethiopia evidenced that place residence, maternal education, distance to a health facility, the decision on place of delivery, and knowledge on obstetric danger signs after delivery was associated with SBA [10]. Educational status [10-14], antenatal care visit [15-18], age group [19], previous pregnancy complication $[10,14,20]$, decision of place of delivery [14], parity [20], husband education [12], wealth index $[11,19,21,22]$, accessing health care [18], sex of provider [23], residence [22], and maternal occupation [20] were identified as significant factors associated with SBA.

Despite the implementation of intensive public health interventions to skilled assisted delivery, the majority of the birth in SSA particularly in East African countries are attained by traditional birth attendants and continued to share the largest portion of global maternal, and newborn mortality. As to our search of literature, there is limited evidence on the magnitude and factors associated with skilled assistant delivery in East African countries.

Therefore, this study aimed to estimate the pooled prevalence and determinants of skilled birth attendance in the 12 East Africa Countries from 2008 to 2017 using recent Demographic and Health Surveys. This could help to design evidence-based public health decisions for enhancing skilled birth attendance at birth to reduce maternal and newborn mortality in these countries.

\section{Methods}

Data source, tool, and sampling procedure

The data was obtained from the measure DHS program at www.measuredhs.com after prepared concept notes about the project. The Demographic and Health Survey (DHS) data were pooled from the 12 East Africa Countries from 2008 to 2017. The recent DHS of Countryspecific dataset was extracted during the specified period. The 12 East Africa Countries in which data extracted include Burundi, Ethiopia, Kenya, Comoros, Madagascar, Malawi, Mozambique, Rwanda, Tanzania, Uganda, Zambia, and Zimbabwe (Table 1). There 20 countries in WHO regions of East Africa. In history, only 14 countries had DHS data. For this study 12 countries were included (Fig. 1). The DHS program adopts standardized methods involving uniform questionnaires, manuals, and field procedures to gather the information that is comparable across countries in the world. DHSs are nationally representative household surveys that provide data from a wide range of monitoring and impact evaluation indicators in the area of population, health, and nutrition with face to face interviews of women age 15 to 49 . The surveys employ a stratified, multi-stage, random sampling design. Information was obtained from eligible women aged 15 to 49 years in each country. 
Detailed survey methodology and sampling methods used in gathering the data have been reported elsewhere [24].

\section{Variables}

\section{Outcome variable}

The response (outcome) variable of this study was a skilled birth attendant. The response variable was generated from the question asked to the women who gave birth within 5 years preceding the survey question "who assisted the delivery?" The response was dichotomized as a health professional and another person. Health professionals include doctors, nurses, nurse/midwife, auxiliary midwife, and others (health officer and health extension workers). Other persons include traditional birth attendance (TBA), traditional health volunteer, community/village health volunteer, neighbors/friends, relatives, others. If a women delivery were assisted by health professional coded as "1", otherwise coded as "0".

\section{Independent variables}

Based on the literature, the independent variables included in this were two types of variables. Individuallevel and community-level variables. Community-level variables include country and residence. The individuallevel variables are age group, marital status, maternal and husband educational status, occupational status, wealth index, parity, ANC visit, wanted pregnancy, number of gestation, accessing health care wealth index, and birth interval.

\section{Operational definition}

Accessing health care: most studies have isolated the travel time and transport cost when looking at access to

Table 1 The DHS years of study and study participants of the skilled birth attendant in the 12 East African Countries from 2008 to 2017

\begin{tabular}{lll}
\hline Eastern Region of Arica & DHS year & Study participants \\
\hline Burundi & 2010 & 13,610 \\
Ethiopia & 2016 & 11,022 \\
Kenya & 2014 & 19,563 \\
Comoros & 2012 & 2880 \\
Madagascar & $2008 / 09$ & 12,407 \\
Malawi & $2015 / 16$ & 17,395 \\
Mozambique & 2011 & 11,477 \\
Rwanda & $2014 / 15$ & 10,051 \\
Tanzania & $2015 / 16$ & 8002 \\
Uganda & 2011 & 15,270 \\
Zambia & 2017 & 13,383 \\
Zimbabwe & $2013 / 14$ & 6418 \\
Total sample size & & $\mathbf{1 4 1 , 4 8 3}$ \\
\hline
\end{tabular}

health facilities. In the DHS data, women were asked whether a range of factors would be a big problem for them in accessing health care. We generated a composite variable using each country DHS standard questions. The questions included:

getting the money needed for treatment (big problem/not a big problem)

\# distance to a health care facility (big problem/not a big problem)

\# having to take transport (big problem/not a big problem)

\# Not wanting to go alone (big problem/not a big problem)

If women face at least one or more of the problems (money, distance, companionship, and permission) we considered as there is health care accessing problem that was our primary interest and we coded as 1 and If they reported no health care accessing out of four (money, distance, companionship, and permission) we code 0 .

\section{Wealth index}

Wealth index is calculated by using principal components analysis (PCA) that involves assigning scores on the indicator variables. In the dataset, the index has five quintiles such as; the lowest quintile (poorest), 2nd quintile (poorer), 3rd quintile (middle), 4th quintile (wealthier), and the 5th quintile (wealthiest). In this study for ease of analysis this variable was recategorized as 'poorest' and 'poorer' were coded as (1) 'poor', the middle was coded as (2) 'middle', and 'wealthier' and 'wealthiest' were coded as (3) 'rich" [25].

Auxiliary midwife:-is a village-level female health worker who is known as the first contact.

\section{Data management and analysis}

The data was cleaned by STATA version 14.1 software. Sample weighting was done for further analysis.

\section{Multi-level analysis}

Since the outcome variable was binary two-level mixedeffects logistic regression analysis was employed. Sampling weight was applied as part of a complex survey design using primary sampling unit, strata, and women's individual weight (V005).

The individual and community level variables associated with skilled birth attendant were checked independently in the bi-variable multilevel logistic regression model and variables which were statistically significant at $p$-value 0.20 in the bi-variable multilevel mixed-effects logistic regression analysis were considered for the final individual and community level model adjustments. In the multivariable multilevel analysis, variables with a $p$ - 


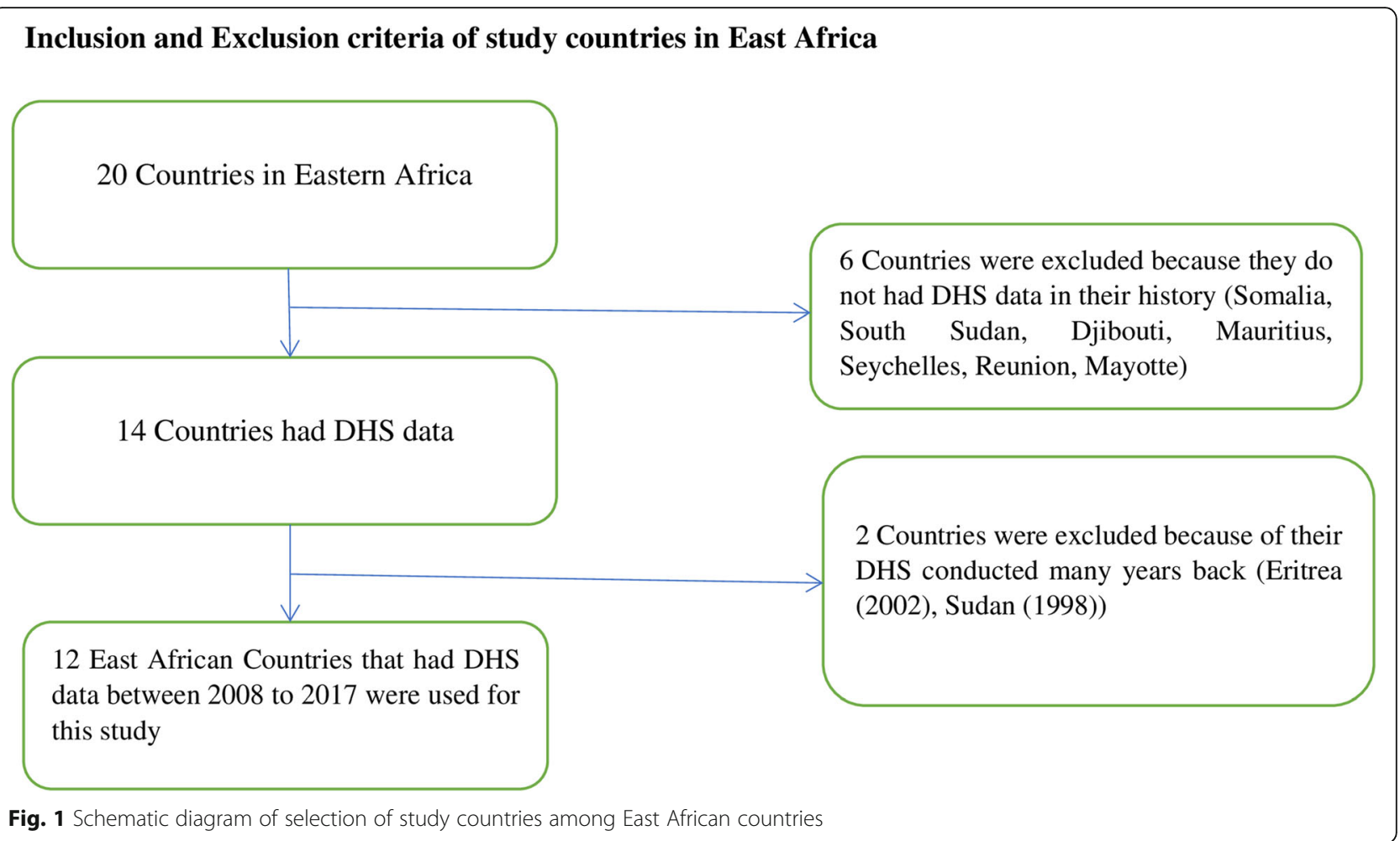

value $\leq 0.05$ were declared as significant determinants of skilled assistance delivery.

\section{Model building}

Four models were fitted. The first was the null model containing no exposure variables which was used to check variation in community and provide evidence to assess random effects at the community level. Then model I was the multivariable model adjustment for individual-level variables and model II was adjusted for community-level factors. In model III, possible candidate variables from both individual and community-level variables were fitted with the outcome variable.

\section{Parameter estimation method}

The fixed effects (a measure of association) were used to estimate the association between the likelihood of skilled birth attendant and explanatory variables at both community and individual level and were expressed as odds ratio with $95 \%$ confidence interval. Regarding the measures of variation (random-effects), Community-level variance with standard deviation, intracluster correlation coefficient (ICC), Proportional Change in Community Variance (PCV), and median odds ratio (MOR) was used.

The aim of the median odds ratio (MOR) is to translate the area level variance in the widely used odds ratio (OR) scale, which has a consistent and intuitive interpretation. The MOR is defined as the median value of the odds ratio between the area at the highest risk and the area at the lowest risk when randomly picking out two areas. The MOR can be conceptualized as the increased risk that (in median) would have if moving to another area with a higher risk.

It is computed by; MOR $=\exp [\sqrt{ }(2 \times \mathrm{Va}) \times 0.6745]$ [26].

Where; VA is the area level variance, and 0.6745 is the 75 th centile of the cumulative distribution function of the normal distribution with mean 0 and variance 1 . See elsewhere for a more detailed explanation [24]. Whereas the proportional change in variance is calculated as [27]

$$
\mathrm{PCV}=[(\mathrm{VA}-\mathrm{VB}) / \mathrm{VA}] * 100
$$

Where; where VA = variance of the initial model, and $\mathrm{VB}=$ variance of the model with more terms.

\section{Results}

\section{Socio-demographic characteristics}

A total of 141,483 women who gave birth in the 5 years preceding each country's DHS survey were included in this study. The median age of women was 28 with IQR of 10 with the majority of women underlie in the age group of 25-34. Most of the women were from Kenya $19,563(13.83 \%)$ and the smallest number of women were included from Comoros 2880(2.04\%). Majority 110, $471(78.08 \%)$ of women were from rural residents. A high number of women 100,261 (70.86\%) were married. Two out of three women had antenatal care visit 93,360(65\%). 
A large number of $80,769(57.09 \%)$ responded that they faced accessing health care service problems (Table 2).

\section{Pooled prevalence of skilled birth attendant}

The pooled prevalence of skilled birth attendants in East African countries was $67.18 \%$ (95\% CI: 66.98, 67.38) with the highest skilled birth attendant in Rwanda (90.68\%) and the lowest skilled birth attendant in Tanzania (11.91\%) (Fig. 2).

\section{Determinants of skill birth attendant at birth in East Africa countries \\ The random-effects analysis results}

The fixed effects (a measure of association) and the random intercepts for skilled birth attendants are presented in Table 2 . The results of the empty model revealed that there was statistically significant variability in the odds of seeking skilled birth attendance with community variance $(\tau=0.79, \quad p$-value $=p<0.001)$. Similarly, the ICC in the empty model implied that $19.39 \%$ of the total variability in skilled assistant delivery was attributed to the differences between communities. Moreover, the MOR was 2.32 (95\% CI 2.22, 2.42) which implied that the odds of giving birth by the skilled birth attendant were 2.32 times higher when respondents moved from low to high-risk communities. This showed that the existence of significant heterogeneity in skilled assistant delivery across different communities. In the full model (model adjusted for both individual and community-level factors) community variance (community variance $=0.075 ; \quad \mathrm{SE}$ 0.0046; $P$-value, $<0.001$ ), remained significant but reduced. About $7.50 \%$ of the total variance of skilled birth attendant delivery can be attributed to the contextual-level factors that remained significant even after considering some contextual risk factors. The proportional change in variance $(\mathrm{PCV})$ in this model was $90.50 \%$ which showed that $90.50 \%$ of community variance observed in the null model was explained by both community and individual level variables (Table 3).

\section{The fixed effects analysis result}

The model with smaller deviance and the largest likelihood (model IV) was best fit the data and the interpretation of the fixed effects was based on this model. Model four was adjusted for both individual and community-level factors. Consequently, respondent's age group, maternal education, husband education, wealth index, ANC visit, multiple gestations, parity, accessing health care, birth interval, residence, and living Country were significantly associated with the skilled birth interval in the East Africa Counties. The odds of SBA delivery among women aged 25-34 and 35-49 years were increased by 14 and $16 \%$ as compared to women age group $15-24(\mathrm{AOR}=1.14,95 \% \mathrm{CI}=1.09,1.18)$ and $(\mathrm{AOR}=$ $1.16,95 \% \mathrm{CI}=1.10,1.23)$ respectively. The odds of obtaining SBA among women of primary and secondary and above educational level were 1.57 and 2.85 times higher as compared to women with no education $(\mathrm{AOR}=1.57,95 \% \mathrm{CI}=$ $1.51,1.63)$ and $(\mathrm{AOR}=2.85,95 \% \mathrm{CI}=2.70,3.01)$ respectively. The odds of obtaining SBA among women of their husband's educational level primary and secondary and above educational level were increased by 11 and $46 \%$ as compared to women with no education $(\mathrm{AOR}=1.11,95 \% \mathrm{CI}=1.07,1.15)$ and $(\mathrm{AOR}=1.46,95 \% \mathrm{CI}=1.40,1.53)$ respectively. The odds of seeking SBA among women wealth status middle and rich were 1.43 and 2.38 times higher as compared to poor women $(\mathrm{AOR}=1.43,95 \% \mathrm{CI}=1.38,1.49)$ and $(\mathrm{AOR}=2.38,95 \% \mathrm{CI}=$ $2.28,2.48)$ respectively. The odds of seeking SBA among women who had ANC visits were increased by $68 \%$ as compared to women who had no ANC visit $(\mathrm{AOR}=1.68$, $95 \% \mathrm{CI}=1.62,1.73$ ). The odds of seeking SBA among women who faced multiple births were 2.06 times higher as compared to women who faced single birth $(\mathrm{AOR}=2.06$, $95 \% \mathrm{CI}=1.96,2.25)$. The odds of obtaining SBA among women of para 2-4 and para $5+$ were decreased by 35 and $56 \%$ as compared to para1 $(\mathrm{AOR}=0.65,95 \% \mathrm{CI}=0.61,0.69$ ) and $(\mathrm{AOR}=0.44,95 \% \mathrm{CI}=0.41,0.47)$ respectively. The odds of obtaining SBA among women of not a big problem in accessing health care were increased by $32 \%$ as compared to women of big problems in accessing health care $(\mathrm{AOR}=$ 0.1.32, $95 \% \mathrm{CI}=1.28,1.36$ ). The odds of obtaining SBA among women deliver with a birth interval greater than 2 and above years were decrease by $9 \%$ as compared to women deliver with less than two-year birth spacing $(\mathrm{AOR}=0.91$, $95 \% \mathrm{CI}=0.87,0.94)$. The odds of seeking SBA among women of the rural resident were decreased by $57 \%$ as compared to urban women $(\mathrm{AOR}=0.43,95 \% \mathrm{CI}=0.41,0.45)$. Living countries had a significant effect on the likelihood of obtaining SBA in the East Africa Countries (Table 3).

\section{Discussion}

The overall aim of this study was to investigate the pooled prevalence and determinates of skilled birth attendant delivery in the 12 East Africa Countries from 2008 to 2017 using recent Demographic and Health Surveys dataset. The pooled prevalence of skilled birth attendants in East African countries was $67.18 \%$ (95\% CI: 66.98, 67.38) with the highest skilled birth attendant in Rwanda (90.68\%) and the lowest skilled birth attendant in Tanzania (11.91\%). This was lower than studies conducted in Namibia $80.3 \%$ [28]. The finding was much higher than studies conducted in Cambodia 19.8\% [17], Bangladesh 35.9\% [22], subSaharan African countries 53\% [15], Ethiopia 28.6\% [29], Togo 66.67\% [19], and Nepal 48\% [30]. The discrepancy might be due to differences in the study period that is Namibia study use DHS 2006/07 while this study 2008\2017. Studies in Cambodia, Bangladesh, Ethiopia, 
Table 2 Socio-demographic, economic, maternal and obstetric characteristic respondents in the 12 East Africa Countries from 2008 to 2017

\begin{tabular}{lll}
\hline Variables & Weighted Frequency $(N=$ & $\begin{array}{l}\text { Percentage } \\
(\%)\end{array}$ \\
\hline Socio-economic and demographic characteristics of respondents
\end{tabular}

\section{Country}

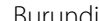

Burundi

13,610

Ethiopia

11,022

Kenya

19,563

Comoros

2880

Madagascar

12,407

Malawi

17,395

Mozambique

11,477

Rwanda

8002

Tanzania

10,051

Uganda

15,270

Zambia

13,383

Zimbabwe

6418

Residence

Urban

31,012

Rural

110,471

Age group

$$
15-24
$$

25-34

67,704

35-49

31,612

Marital status
Single

Married

$$
41,222
$$

100,261

Maternal education

No education

33,631

Primary

75,945

Secondary and

31,906

above

\section{Husband education}

No education $\quad 48,411$

Primary 59,332

Secondary and $\quad 33,739$

above

\section{Maternal Occupation}

Had no

47,153

Occupation

Had Occupation

94,330

Wealth Index

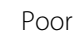

64,367

Middle

27,586

49,528
9.62

7.79

Table 2 Socio-demographic, economic, maternal and obstetric characteristic respondents in the 12 East Africa Countries from

\begin{tabular}{|c|c|c|}
\hline Variables & $\begin{array}{l}\text { Weighted Frequency }(N= \\
141,483)\end{array}$ & $\begin{array}{l}\text { Percentage } \\
(\%)\end{array}$ \\
\hline \multicolumn{3}{|c|}{ Maternal and Obstetrics characteristics of respondents } \\
\hline \multicolumn{3}{|l|}{ ANC visit } \\
\hline No ANC visit & 48,122 & 34.01 \\
\hline Had ANC visit & 93,360 & 65.99 \\
\hline \multicolumn{3}{|l|}{ Wanted Pregnancy } \\
\hline Yes & 121,189 & 85.66 \\
\hline No & 20,294 & 14.34 \\
\hline \multicolumn{3}{|l|}{ Number of gestation } \\
\hline Single & 136,979 & 96.82 \\
\hline Multiple & 4054 & 3.18 \\
\hline \multicolumn{3}{|l|}{ Parity } \\
\hline 1 & 22,141 & 15.65 \\
\hline $2-4$ & 72,857 & 51.50 \\
\hline $5+$ & 46,848 & 32.86 \\
\hline \multicolumn{3}{|c|}{ Accessing health Care } \\
\hline Big problem & 80,769 & 57.09 \\
\hline Not bog problem & 60,714 & 42.91 \\
\hline \multicolumn{3}{|l|}{ Birth Interval } \\
\hline $\begin{array}{l}\text { Less than } 24 \\
\text { month }\end{array}$ & 52,549 & 37.14 \\
\hline $\begin{array}{l}24 \text { month and } \\
\text { above }\end{array}$ & 88,934 & 62.86 \\
\hline
\end{tabular}
2008 to 2017 (Continued)

29.14

70.86

23.77

53.68

22.55

34.22

41.94

23.85

33.33

66.67

45.49

19.50

35.01

Togo, and Nepal are not representative of the East Africa region since a single country study. The study conducted sub-Saharan Africa include included 34 countries, cultural barriers towards utilization of maternal health services, and different infrastructure across the regions [31].

In East Africa, skilled birth attendance at birth was significantly varied across counties, ranging from $11.91 \% \%$ has seen a $55 \%$ decline in the maternal death ratio. An enormous success that qualified Rwanda to be among the nine developing countries which achieved the millennium development goals 4 and 5 (MDGs). Though skilled birth attendance stands high at $91 \%$, the coverage of completed 4 Ante Natal Care visits remains low at 44\% [32]. While in Tanzania according to the Ministry of the health of the country report there is the inadequate implementation of pro-poor policies, weak health infrastructure, limited access to quality health services, inadequate human resources, shortage of skilled health providers [33]. in Tanzania to $90.68 \%$ in Rwanda. Since 2010, Rwanda

In the multilevel multivariable logistic regression analysis age group, maternal education, husband education, 
wealth index, antenatal care visit, number of gestation, parity accessing health care, birth interval, residence, and living countries were determinants of skilled birth attendance at birth in the East Africa Countries.

This study evidenced that as the women age group increases the likelihood of obtaining skilled birth attendance at birth also increases. This finding was supported by study findings from Nepal [12] and contradicts studies from Ghana [34]. This could be explained by the fact that as the age of women increases they gained experience and knowledge about the benefit of skilled birth attendants from earlier pregnancies.

Women and her husband who have achieved primary education and higher were more likely to skilled birth attendants than women her husband who didn't have formal education. This finding is supported by different studies conducted in Vietnam, Togo, Bangladesh, SubSaharan Africa, Ethiopia [10, 11, 15, 19, 22]. The finding is also supported by studies in Uganda and Ghana [18, 35]. Attaining education among women and her husband can influence the decision on skilled birth attendance at birth in different ways. Educated women and men would know the benefit of skilled birth attendance at birth and the danger of giving birth by an unskilled professional through reading newspapers, mass media, and from different social media. Overall, educated women and men had good health-seeking behavior and the use of health services [36].

Wealth index had a significant association on the likelihood of skilled birth attendance at birth in the East Africa Countries. This study evidenced that likelihood of obtaining skilled birth attendance at birth was higher among women of middle and rich wealth status as compared to poor women. This finding was supported by studies conducted in Vietnam [11], Togo [19], Bangladesh [13, 22], Ethiopia [29]. The possible justification might be due to women with medium and rich household wealth index were more likely to be able to pay for care-seeking costs such as transportation, medications, and any associated costs and also can get easily information about the benefit of obtaining skilled birth attendance at birth [28].

\section{Skilled birth attendant in the 12 East African countries from 2008 to 2017}

\begin{tabular}{|c|c|c|c|c|c|c|}
\hline \multirow[b]{2}{*}{ Country } & \multirow{2}{*}{$\begin{array}{l}\text { DHS } \\
\text { year }\end{array}$} & $\begin{array}{l}\text { Skilled } \\
\text { birth }\end{array}$ & \multirow{2}{*}{\multicolumn{2}{|c|}{ Total }} & \multirow[b]{2}{*}{ ES $(95 \% \mathrm{Cl})$} & \multirow{2}{*}{$\begin{array}{l}\% \\
\text { Weight }\end{array}$} \\
\hline & & attendant & & & & \\
\hline Burundi & 2010 & 11587 & 13611 & & - $85.13(84.53,85.73)$ & 11.67 \\
\hline Ethiopia & 2016 & 3053 & 11023 & $\bullet$ & $27.70(26.86,28.53)$ & 5.98 \\
\hline Kenya & 2014 & 12099 & 19564 & ? & $61.84(61.16,62.52)$ & 9.00 \\
\hline Comoros & 2012 & 2413 & 2880 & & - $83.78(82.44,85.13)$ & 2.30 \\
\hline Madagascar & $2008 / 09$ & 5479 & 12407 & $\bullet$ & $44.16(43.29,45.03)$ & 5.46 \\
\hline Malawi & $2015 / 16$ & 15620 & 17395 & & - $89.80(89.35,90.25)$ & 20.61 \\
\hline Mozambeque & 2011 & 6158 & 11478 & - : & $53.65(52.74,54.56)$ & 5.01 \\
\hline Rwanda & $2014 / 15$ & 7257 & 8003 & & - $90.68(90.04,91.32)$ & 10.28 \\
\hline Tanzania & $2015 / 16$ & 1197 & 10052 & $\bullet$ & $11.91(11.27,12.54)$ & 10.40 \\
\hline Uganda & 2011 & 11482 & 15270 & & $75.19(74.51,75.88)$ & 8.89 \\
\hline Zambia & 2017 & 8593 & 13383 & $\bullet$ & $64.21(63.40,65.02)$ & 6.32 \\
\hline Zimbabwe & $2013 / 14$ & 5015 & 6418 & & * $78.14(77.13,79.15)$ & 4.08 \\
\hline \multicolumn{4}{|c|}{ Overall (I-squared $=100.0 \%, p=0.000)$} & & $67.18(66.98,67.38)$ & 100.00 \\
\hline & & & $\begin{array}{c} \\
-91.3\end{array}$ & 0 & $\begin{array}{l}1 \\
91.3\end{array}$ & \\
\hline
\end{tabular}


Table 3 Multivariable multilevel logistic regression analysis of both individual and community-level factors associated with skilled birth attendant delivery in East Africa countries from 2008 to 2017

\begin{tabular}{|c|c|c|c|c|}
\hline \multirow{3}{*}{$\begin{array}{l}\text { Individual and } \\
\text { community-level } \\
\text { variables }\end{array}$} & \multicolumn{4}{|l|}{ Models } \\
\hline & Null model & Model I & Model II & Model III \\
\hline & AOR $(95 \% \mathrm{Cl})$ & AOR $(95 \% \mathrm{Cl})$ & AOR $(95 \% \mathrm{Cl})$ & AOR $(95 \% \mathrm{Cl})$ \\
\hline \multicolumn{5}{|l|}{ Age group } \\
\hline $15-24$ & & 1 & & 1 \\
\hline $25-34$ & & $1.19(1.15,1.24)$ & & $1.14(1.09,1.18)^{*}$ \\
\hline $35-49$ & & $1.21(1.15,1.27)$ & & $1.16(1.10,1.23)^{*}$ \\
\hline \multicolumn{5}{|l|}{ Marital status } \\
\hline Single & & 1 & & 1 \\
\hline Married & & $0.86(0.83,0.88)$ & & $1.04(0.99,1.07)$ \\
\hline \multicolumn{5}{|l|}{ Maternal education } \\
\hline No education & & 1 & & 1 \\
\hline Primary & & $1.60(1.55,1.65)$ & & $1.57(1.51,1.63)^{*}$ \\
\hline Secondary and above & & $2.65(2.54,2.77)$ & & $2.85(2.70,3.01)^{*}$ \\
\hline \multicolumn{5}{|l|}{ Husband education } \\
\hline No education & & 1 & & 1 \\
\hline Primary & & $1.16(1.13,1.20)$ & & $1.11(1.07,1.15)^{*}$ \\
\hline Secondary and above & & $1.63(1.57,1.69)$ & & $1.46(1.40,1.53)^{*}$ \\
\hline \multicolumn{5}{|l|}{ Maternal Occupation } \\
\hline Had no Occupation & & 1 & & 1 \\
\hline Had Occupation & & $1.19(1.16,1.22)$ & & $0.95(0.92,1.02)$ \\
\hline \multicolumn{5}{|l|}{ Wealth Index } \\
\hline Poor & & 1 & & \\
\hline Middle & & $1.40(1.36,1.45)$ & & $1.43(1.38,1.49)^{*}$ \\
\hline Rich & & $2.14(2.33,2.49)$ & & $2.38(2.28,2.48)^{*}$ \\
\hline \multicolumn{5}{|l|}{ ANC visit } \\
\hline No ANC visit & & 1 & & 1 \\
\hline Had ANC visit & & $1.70(1.66,1.75)$ & & $1.68(1.62,1.73)^{*}$ \\
\hline \multicolumn{5}{|l|}{ Wanted Pregnancy } \\
\hline Yes & & 1 & & 1 \\
\hline No & & $1.14(1.10,1.19)$ & & $0.91(0.87,1.03)$ \\
\hline \multicolumn{5}{|l|}{ Number of gestation } \\
\hline Single & & 1 & & 1 \\
\hline Multiple & & $1.92(1.78,2.06)$ & & $2.06(1.90,2.25)^{*}$ \\
\hline \multicolumn{5}{|l|}{ Parity } \\
\hline 1 & & 1 & & 1 \\
\hline $2-4$ & & $0.73(0.70,0.77)$ & & $0.65(0.61,0.69)^{*}$ \\
\hline $5+$ & & $0.47(0.44,0.50)$ & & $0.44(0.41,0.47)^{*}$ \\
\hline \multicolumn{5}{|l|}{ Accessing health Care } \\
\hline Big problem & & 1 & & 1 \\
\hline Not bog problem & & $1.14(1.10,1.19)$ & & $1.32(1.28,1.36)^{*}$ \\
\hline \multicolumn{5}{|l|}{ Birth Interval } \\
\hline Less than 24 month & & 1 & & 1 \\
\hline 24 month and above & & $0.96(0.93,0.99)$ & & $0.91(0.87,0.94)^{*}$ \\
\hline
\end{tabular}


Table 3 Multivariable multilevel logistic regression analysis of both individual and community-level factors associated with skilled birth attendant delivery in East Africa countries from 2008 to 2017 (Continued)

\begin{tabular}{|c|c|c|c|c|}
\hline \multirow{3}{*}{$\begin{array}{l}\text { Individual and } \\
\text { community-level } \\
\text { variables }\end{array}$} & \multicolumn{4}{|l|}{ Models } \\
\hline & Null model & Model I & Model II & Model III \\
\hline & AOR $(95 \% \mathrm{Cl})$ & AOR $(95 \% \mathrm{Cl})$ & AOR $(95 \% \mathrm{Cl})$ & AOR $(95 \% \mathrm{Cl})$ \\
\hline \multicolumn{5}{|l|}{ Residence } \\
\hline Urban & & & 1 & 1 \\
\hline Rural & & & $0.18(0.17,0.19)$ & $0.43(0.41,0.45)^{*}$ \\
\hline \multicolumn{5}{|l|}{ Country } \\
\hline Burundi & & & $0.58(0.53 .0 .64)$ & $0.77(0.70,0.85)^{*}$ \\
\hline Ethiopia & & & $0.039(0.036,0.043)$ & $0.05(0.04,0.06)^{*}$ \\
\hline Kenya & & & $0.09(0.08,0.10)$ & $0.09(0.085,0.104)^{*}$ \\
\hline Comoros & & & $0.37(0.33,0.43)$ & $0.55(0.47,0.63)^{*}$ \\
\hline Madagascar & & & $0.37(0.33,0.43)$ & $0.065(0.05,0.071)^{*}$ \\
\hline Malawi & & & $0.07(0.06,0.078)$ & $1.01(0.91,1.12)$ \\
\hline Mozambique & & & $1.11(1.01,1.23)$ & $0.12(0.11,0.13)^{*}$ \\
\hline Rwanda & & & 1 & 1 \\
\hline Tanzania & & & $\begin{array}{l}0.006(0.0062, .007) \\
0)\end{array}$ & $0.005(0.004,0.0057)^{*}$ \\
\hline Uganda & & & $0.27(0.25,0.29)$ & $0.27(0.25,0.30)^{*}$ \\
\hline Zambia & & & $0.13(0.11,0.14)$ & $0.12(0.11,0.13)^{*}$ \\
\hline Zimbabwe & & & $0.33(0.30,0.37)$ & $0.19(0.17,0.21)^{*}$ \\
\hline \multicolumn{5}{|l|}{ Random effects } \\
\hline Community variance(SE) & $0.79(0.04) 1)$ & $0.446(0.026)$ & $0.52(0.03)$ & $0.075(0.0046)$ \\
\hline ICC\% & $19.39 \%$ & $11.94 \%$ & 13.71 & $7.50 \%$ \\
\hline PCV\% & 1 & $43.54 \%$ & 34.17 & $90.50 \%$ \\
\hline MOR & $2.32(2.22,2.42))$ & $1.88(1.80,1.95)$ & $1.98(1.90,2.06)$ & $1.63(1.58,1.69)$ \\
\hline \multicolumn{5}{|l|}{ Model comparison } \\
\hline Log-likelihood ratio & $-89,568$ & $-80,035$ & $-68,848$ & $-62,929$ \\
\hline Deviance & 179,136 & 160,070 & 137,696 & 125,858 \\
\hline
\end{tabular}

NB: * $=$ Significant at $P$-value $<0.05$ ICC = Intraclass Correlation Coefficient, MOR Median Odds Ratio, PCV Proportional Change in Variance, SE Standard Error, AOR Adjusted Odds Ratio, ANC Antenatal Care

This study revealed that women who had antennal care visits had a significant association with the likelihood of obtaining skilled birth attendance at birth as compared to women who had no antenatal care visits. This finding was supported by studies Zambia [9], Sierra Leone, Niger, and Mali [16], Ethiopia [10], and Uganda [35]. The possible justification might be due to women during ANC follow up got health education about the advantage of skilled birth attendance at birth. Therefore, women during ANC follow up will got behavioral change towards skilled birth attendance at birth.

The other most significant determinants of skilled birth attendance at birth in this study was the type of gestation. Mothers who have multiple gestations were more likely to obtain skilled birth attendants at birth than singletons. This finding was supported studies conducted from 60 low and middle-income countries [37]. This might be due to the reason that mothers with multiple gestations are at special risk of pregnancyrelated complications like obstructed labor, birth asphyxia, antepartum hemorrhage, preeclampsia, and postpartum hemorrhage [38] this could make women seek to obtain skilled birth attendance at birth.

There is a strong relationship between parity and skilled birth attendance at birth. This study evidenced that as the number of children in the family increases the likelihood of obtaining skilled birth attendance at birth decreases. This finding was supported by studies conducted in Nigeria [39], Ethiopia [29], Uganda [35]. The possible justification might be due to multiparous women commonly prefer to give birth at home this results reduction of obtaining skilled birth attendance at birth. 
Accessing health care had a significant effect on the likelihood of obtaining skilled birth attendance at birth. The current study evidenced that women who reported accessing health care not big problem increases the likelihood of obtaining skilled birth attendance at birth as compared to women who reported accessing health care big problem. This finding was supported by studies conducted in Ethiopia [10], Ghana [40]. This could be due to the reason that health care access problem is a predisposing factor for seeking skilled birth attendance at birth, and to make maternal health care services available and accessible to the community. This is due to the reason that assessing health care services is important for promoting and maintaining their health, reducing unnecessary disability, and premature death. Besides, accessibility is related to transport issues, financial burden, and long distance to the health facility.

This study evidenced that the odds of obtaining skilled birth attendance at birth among women deliver 2 years and above birth interval were decreased as compared to women deliver less than two-year birth interval. This finding was supported by studies conducted in South East Asia [41]. The possible justification might be due to short birth spacing mothers may face pregnancy complications than long birth spacing which may result in seeking to obtain skilled birth attendance at birth.

Other important determinants of skilled birth attendance at birth in the East Africa counties were residence. The current study evidenced that the odds of obtaining skilled birth attendance at birth among women who reside in the rural area decrease as compared to urban women. This finding was supported by studies conducted in Bangladesh [13, 22], Ghana [42], South Sudan [21], Namibia [28]. The possible justification might be due to there may be high economic concentration, better infrastructure, education, health facilities in urban areas, which may contribute to inequalities in delivery by skilled attendants across all countries in the region.

\section{Strengths and limitations of the study}

Pertaining to the strengths, the dataset used in this study was obtained from nationally representative and the variables in the 12 East Africa DHS dataset were the same hence comparable across all countries. The study was population-based with a response rate of $>90 \%$. The data were pooled together to create a large sample size and increase the generalizability of skilled birth attendant reported within 5 years preceding each country survey which ranges from 2008 to 2017 and was able to identify the significant determinants of skilled birth attendant across the 12 East African Countries to inform policymakers and planners for their intervention to prioritize.
Regarding the limitations, the finding from this study may not establish a true causal relationship between the outcome variable and independent variables due to the cross-sectional nature of the study design. The data was collected based on self-report from mothers within 5 years preceding the survey and this could be a potential source of recall and misclassification bias. Six countries had no DHS data in East Africa and the result of this study may not representative of the entire East Africa country.

\section{Conclusions}

Skilled birth attendance at birth in the East Africa countries was low. Age, women and husband education, wealth index, ANC visit, number of gestation, accessing health care, residence, and living countries were major determinants of skilled birth attendance. Strategies to increase the accessibility and availability of healthcare services, and financial support that enables mothers from poor households to use health services will be beneficial. Health education targeting mothers and their partner with no education are vital to increasing their awareness about the importance of skilled birth attendance at birth.

\section{Abbreviations \\ ANC: Antenatal Care; AOR: Adjusted Odds Ratio; Cl: Confidence Interval; DHS: Demographic Health Survey; ICC: Intra-class Correlation Coefficient; LLR: Log-likelihood Ratio; LR: Likelihood Ratio; MOR: Median Odds Ratio; SBA: Skilled Birth Attendance; SSA: Sub-Saharan Africa; WHO: World Health Organization}

\section{Acknowledgments}

We greatly acknowledge measure DHS program for granting access to the East African DHS data sets.

\section{Authors' contributions}

ZTT and GAT conceived the study. ZTT and GAT analyzed the data, drafted the manuscript, and reviewed the article. ZIT and GAT extensively reviewed the article. All authors read and approved the final manuscript.

Funding

No funding was obtained for this study.

Availability of data and materials

Data is available online and you can access it from www.measuredhs.com.

\section{Ethics approval and consent to participate}

The study was based on secondary analysis of existing survey data with all identifying information removed. Permission for data access was obtained from measure demographic and health survey through an online request from http://www.measuredhsprogram.com.

Consent for publication

Not applicable since the study was a secondary data analysis.

Competing interests

Authors declare that they have no conflict of interest.

Received: 20 May 2020 Accepted: 23 November 2020

Published online: 30 November 2020

References

1. WHO. Maternal mortality fact sheet. 2018. 
2. WHO U. UNFPA, World Bank Group, and the United Nations Population Division. Trends in Maternal Mortality: 2000 to 2017. Geneva: World Health Organization; 2019.

3. Alkema L, Chou D, Hogan D, Zhang S, Moller A-B, Gemmill A, et al. National, regional ang global levels and trend in MMR between 1990 and 2015. Lancet. 2016;387(10017):462-74.

4. Johnston RB. Arsenic and the 2030 Agenda for sustainable development. Arsen Res Glob Sustain - Proc 6th Int Congr Arsen Environ AS 2016. 2016; $12-4$.

5. WHO. Skilled Birth Attendants [Internet], vol. 2006. Geneva: World Health Organization; 2008. p. 65-7. Available from: http:/www.who.int/ reproductive_health/global_monitoring/data.html\%0A. http://www.who.int/ maternal_child_adolescent/events/2008/mdg5/factsheet_sba.pdf.

6. Data $\mathrm{GHO}(\mathrm{GHO})$. Skilled attendants at birth [Internet]. 2019. Available from: https://www.who.int/gho/maternal_health/skilled_care/skilled_birth_ attendance_text/en/.

7. Vallin J. Can skilled attendance at delivery reduce maternal mortality in developing countries? Espace Popul Societes. 1985;1985-3:515-40.

8. WHO. Organization WH. World health statistics 2010: World Health Organization; 2010. Available from: https://books.google.iq/books?hl=en\&lr= \&id=Z69vxfRFFIsC\&oi=fnd\&pg=PA1\&dq=Organization+WH.+World +health+ statistics+2010:+World+Health+Organization\%3B+2010.\&ots= cHQRfoFHaz\&sig=ccs76XEW9XZMxINZJFrwogjEiLs\&redir_esc $=y \# v=$ onepage\&q=Organization. WH.Worldhealth.

9. Jacobs C, Moshabela M, Maswenyeho S, Lambo N, Michelo C. Predictors of antenatal care, skilled birth attendance, and postnatal care utilization among the remote and poorest rural communities of Zambia: a multilevel analysis. Front Pub Health. 2017;5:11.

10. Ayele GS, Melku AT, Belda SS. Utilization of skilled birth attendant at birth and associated factors among women who gave birth in the last 24 months preceding the survey in Gura Dhamole Woreda, bale zone, Southeast Ethiopia. BMC Public Health. 2019;19(1):1-14.

11. Do M. Utilization of skilled birth attendants in public and private sectors in Vietnam. J Biosoc Sci. 2009;41(3):289-308 2009/03/04. Available from: https://www.cambridge.org/core/journals/journal-of-biosocial-science/ article/utilization-of-skilled-birth-attendants-in-public-and-private-sectors-invietnam/91FD8FE6C2922D251BOFBE2117F854AA.

12. Dhakal S, van Teijlingen E, Raja EA, Dhakal KB. Skilled care at birth among rural women in Nepal: practice and challenges. J Heal Popul Nutr. 2011; 29(4):371-8 2011/10/01. Available from: https://www.ncbi.nlm.nih.gov/pmc/ articles/PMC3190368/pdf/jhpn0029-0371.pdf.

13. Bhowmik J, Biswas RK, Woldegiorgis M. Antenatal care and skilled birth attendance in Bangladesh are influenced by female education and family affordability: BDHS 2014. Public Health. 2019;170:113-21 2019/04/17.

14. Adewemimo AW, Msuya SE, Olaniyan CT, Adegoke AA. Utilisation of skilled birth attendance in Northern Nigeria: a cross-sectional survey. Midwifery. 2014;30(1):e7-13 2013/10/22.

15. Woldegiorgis MA, Hiller J, Mekonnen W, Meyer D, Bhowmik J. Determinants of antenatal care and skilled birth attendance in sub-Saharan Africa: A multilevel analysis. Heal Serv Res. 2019;54(5):1110-8 2019/05/16.

16. Ameyaw EK, Dickson KS. Skilled birth attendance in Sierra Leone, Niger, and Mali: analysis of demographic and health surveys. BMC Public Health. 2020; 20(1):1-10.

17. Yanagisawa $S$, Oum S, Wakai S. Determinants of skilled birth attendance in rural Cambodia. Trop Med Int Heal. 2006;11(2):238-51 2006/02/03.

18. Manyeh AK, Akpakli DE, Kukula V, Ekey RA, Narh-Bana S, Adjei A, et al. Sociodemographic determinants of skilled birth attendant at delivery in rural southern Ghana. BMC Res Notes. 2017;10(1):1-7.

19. Mati K, Adegoke KK, Michael-Asalu A, Salihu HM. Health insurance coverage and access to skilled birth attendance in Togo. Int J Gynaecol Obs. 2018; 141(2):181-8 2018/01/26.

20. Agho KE, Dibley MJ, Islam N, Islam MT, Yoshimura Y. Practices and determinants of delivery by skilled birth attendants in Bangladesh. Matern Child Heal J. 2014;11:86 2016/03/11.Available from: https://reproductivehealth-journal.biomedcentral.com/track/pdf/10.1186/1742-4755-11-86.

21. Letamo G, Bariagaber H, Mugo NS. Risk Factors for Non-use of Skilled Birth Attendants: Analysis of South Sudan Household Survey, 2010. PLoS One. 2016;20(6):1266-79 2017/09/15. Available from: https://journals.plos.org/ plosone/article/file?id=10.1371/journal.pone.0184688\&type=printable.

22. Kibria GMA, Ghosh S, Hossen S, Barsha RAA, Sharmeen A, Uddin SMI. Factors affecting deliveries attended by skilled birth attendants in Bangladesh. Matern
Heal Neonatol Perinatol. 2017;3:7 2017/03/24. Available from: https:// mhnpjournal.biomedcentral.com/track/pdf/10.1186/s40748-017-0046-0.

23. Nyongesa C, Xu X, Hall JJ, Macharia WM, Yego F, Hall B. Factors influencing choice of skilled birth attendance at ANC: evidence from the Kenya demographic health survey. BMC Pregnancy Childbirth. 2018;18(1):88 2018/ 04/11. Available from: https://www.ncbi.nlm.nih.gov/pmc/articles/PMC5891 962/pdf/12884_2018_Article_1727.pdf.

24. Demographic T, Program HS. Guide to DHS Statistics.

25. Healthy People 2020. DHS wealth Index construction. 2001;43. Available from: http://www.dhsprogram.com/publications/publication-WP60-WorkingPapers.cfm.

26. Goldstein H, Browne W, Rasbash J. Partitioning variation in multilevel models. Underst Stat Stat Issues Psychol Educ Soc Sci. 2002; (4):223-31.

27. Merlo J, Chaix B, Yang M, Lynch J, Råstam L. A brief conceptual tutorial on multilevel analysis in social epidemiology: interpreting neighbourhood differences and the effect of neighbourhood characteristics on individual health. J Epidemiol Community Health. 2005;59(12):1022-8.

28. Zere E, Oluwole D, Kirigia JM, Mwikisa CN, Mbeeli T. Inequities in skilled attendance at birth in Namibia: a decomposition analysis. BMC Pregnancy Childbirth. 2011;11:1-10

29. Wilunda C, Quaglio G, Putoto G, Takahashi R, Calia F, Abebe D, et al. Determinants of utilisation of antenatal care and skilled birth attendant at delivery in South West Shoa Zone, Ethiopia: a cross sectional study. Reprod Heal. 2015;12:74 2015/10/04. Available from: https://repository.kulib.kyoto-u. ac.jp/dspace/bitstream/2433/201547/1/s12978-015-0067-y.pdf.

30. Choulagai BP. Skilled birth attendant services in Nepal overcoming barriers to utilization, vol. 7; 2017. p. 8.

31. Walton LM, Brown D. Cultural barriers to maternal health care in rural Bangladesh. J Health Ethics, Fall. 2012.

32. UNFPA. Maternal Health Rwanda. 2019.

33. Huang $B$, Yvon $K$, Fischer P. The national road map strategic plan to accelerate reduction of maternal, newborn and child deaths in Tanzania 2008 - 2015. J Alloys Compd. 2018;210(1-2):243-6.

34. Ameyaw EK, Tanle A, Kissah-Korsah K, Amo-Adjei J. Women's health decision-making autonomy and skilled birth attendance in Ghana. Int J Reprod Med. 2016;2016:1-9.

35. Kwagala B, Nankinga O, Wandera SO, Ndugga P, Kabagenyi A. Empowerment, intimate partner violence and skilled birth attendance among women in rural Uganda. Reprod Heal. 2016;13(1):53 2016/05/05. Available from: https://reproductive-health-journal.biomedcentral.com/track/ pdf/10.1186/s12978-016-0167-3.

36. Thompson AE, Anisimowicz Y, Miedema B, Hogg W, Wodchis WP, AubreyBassler $\mathrm{K}$. The influence of gender and other patient characteristics on health care-seeking behaviour: a QUALICOPC study. BMC Fam Pract. 2016; 17(1):1-7 Available from: https://doi.org/10.1186/s12875-016-0440-0.

37. Bellizzi S, Sobel H, Betran AP, Temmerman M. Early neonatal mortality in twin pregnancy: findings from 60 low- and middle-income countries. J Glob Health. 2018:8(1):1-14.

38. Rao A, Sairam S, Shehata H. Obstetric complications of twin pregnancies. Best Pract Res Clin Obstet Gynaecol. 2004;18(4):557-76.

39. Belda SS, Olakunde BO, Adeyinka DA, Mavegam BO, Olakunde OA, Yahaya $H B$, et al. Factors associated with skilled attendants at birth among married adolescent girls in Nigeria: evidence from the Multiple Indicator Cluster Survey, 2016/2017. BMC Public Health. 2019;11(6):545-50 2019/11/13. Available from: https://bmcpublichealth.biomedcentral.com/track/pdf/10.11 86/s12889-019-7818-6.

40. Apanga PA, Awoonor-Williams JK. Improving Skilled Birth Attendance in Ghana: An Evidence-Based Policy Brief. J Heal Care Poor Underserved. 2017; 28(3):1056-65 2017/08/15. Available from: https://muse.jhu.edu/article/6665 98/pdf.

41. Peng JY. The role of traditional birth attendants in family planning programs in Southeast Asia. Int J Gynecol Obstet. 1979;17(2):108-13.

42. Sakeah E, Doctor HV, McCloskey L, Bernstein J, Yeboah-Antwi K, Mills S. Using the community-based health planning and services program to promote skilled delivery in rural Ghana: socio-demographic factors that influence women utilization of skilled attendants at birth in northern Ghana. BMC Public Health. 2014;14:344 2014/04/12.

\section{Publisher's Note}

Springer Nature remains neutral with regard to jurisdictional claims in published maps and institutional affiliations. 